peller speed was 5o r.p.m. The motor weighed about 2 rolbs,, so the power weight ratio was about $26 \mathrm{lbs}$. per h.p.

The current was generated by a primary battery containing chromic and hydrochloric acids, and the electrodes were of platinised silver and zinc. This battery weighed 880 olbs., so that the power weight ratio of the entire power plant was about I36lbs. per h.p. It should be stated that Captain C. Renard was responsible for the general design of the dirigible while the power plant was designed by Captain R. A. Krebs, and that these two were alone on board during the trial.

\title{
CORRESPONDENCE
}

\section{Metal Construction}

\section{To the Editor of the Journat of the Royal Aeronautical, Society.}

Dear Captain Pritchard,-In the issue of the Royal Aeronautical Society's Journal for August, 1933, the following appears on page 690:-

"The first all-metal aeroplane constructed in this country was the

"Short 'Silver Streak, which appeared in 1919."

I do not think this is correct. I have an impression that in the early years of the war an all-metal aeroplane was constructed of tubes, but it was not a success, owing to its weight and lack of adequate strength.

I know, however, that in I9I 8 my firm, the Steel Wing Company, successfully completed in steel the wings for a machine known as the MR. 1 , and this machine was flown in the latter part of 1918.

As you know, the construction of fuselages in metal was a comparatively easy problem to solve, the difficulty in metal aeroplane construction was to produce a wing structure which would equal the performance of wooden wing structure in weight and strength.

The Steel Wing Company solved this problem by the use of corrugated strip in 1916.

I have for several years ceased to have any connection with the aeroplane industry, and in consequence have not access to the necessary records to verify the statement, but I believe it to be the fact, that a form of steel wing, designed and made by my late firm in 1922 , is, with very slight modifications, still in use in the D.H. $9 \mathrm{~A}$ and its successors, the Wapiti and Wallace machines, i.e., the Steel Wing Company's designs and method of construction for steel aeroplane wings has not, in any essential particular, been improved on in more than ten years.

I have also heard, but I cannot verify the fact, that one at least of the machines which flew over Everest had this design of wing, and from such casual inspection as in recent years I have been able to make of present-day aeroplanes, it seems to me that most of them embody in one form or other the principles on which the Steel Wing Company solved the problem of metal wing construction nearly seventeen years ago.

I have no desire for the limelight, but I think it is only fair that credit should be given where it is due, especially to the men who, as designers or engineers, 
helped me to solve the problem of the construction of aeroplanes in metal. I have especially in mind Mr. Donald Emby, Whit. Exb., Mr. Brian Martin, B.Sc., and Mr. Leo Martin.

Perhaps you could in some way put this matter right, if only in the interests of historical accuracy, which I think concerns the R.Ae.S.

$$
\begin{aligned}
& \text { Yours very sincerely, } \\
& \text { Dermot J. Mooney. }
\end{aligned}
$$

(Mr. Mooney's letter is one of considerable importance and interest and correspondence on the subject of metal construction in its early stages is invited. As Mr. Mooney remarks, the problem of metal fuselages was comparatively easy to solve. M. Esnault-Pelterie took out patents for a welded steel tubular construction and $\mathrm{Mr}$. (now Major) A. R. Low incorporated a considerable number of improvements, as early as I9II-I2, though handicapped by the lack of a sufficiently high tensile steel. In the war, round about late r9i6--early igi7, speaking from memory, the Admiralty carried out tests with steel spars. In a paper read before the Society by Dr. A. P. Thurston in May, IgI9, detailed account of the work done up to that date is given. In the discussion Major Low claimed that he built the first all-metal machine, but the weight of the wings was too great and they had to be scrapped for wood. Mr. Mooney also drew attention to the fact that none of the construction actually described in Dr. Thurston's lecture had been built into a complete metal wing, while some of the all-steel wings of his own company had been actually tested in flight.

In his lecture before the Society in 1923 Professor $H$. Junkers describes his method of construction and his first steel aeroplane, the J.I, which, according to the official report of the German Army authorities in 1916, had a speed of $170 \mathrm{~km}$. per hour, with an engine of $120 \mathrm{~h} . \mathrm{p}$. and total weight of $\mathrm{I}$,oro $\mathrm{kg}$. "The construction of my metal aeroplanes is based on a patent, granted to me as far back as 1910," to quote from the lecture. That patent shows the form of construction, but does not state it is in metal. In $19 \mathrm{I} 7$ was completed the J.4 in duralumin.-EDITOR.)

\section{RE VIE W S}

\section{First Over Everest}

By Air Commodore Fellows, L. V. Stewart Blacker, Col. P. T. Etherton, Sq.-Ldr. the Marquess of Clydesdale, M.P., and Geoffrey Barkas. Published by John Lane. Price 12/6.

The urge to explore the unknown is a potent force which attacks some men of all nations, but especially the British. It was possibly responsible for the advance across Europe of the Aryan invaders in the dawn of history, and it was certainly one of the chief motives which led to the exploration of the seas of the world in Elizabethan times. Nowadays the opportunities for indulging in exploration are more limited, but that the urge is still there is proved by the frequency of Polar expeditions and by this flight.

In olden times the result of expeditions of this type was frequently the annexation of previously unknown lands, nowadays the result desired is the acquisition of more knowledge about the earth, and of this latter type the Everest Expedition is an excellent example. Everest is not only the highest mountain in the world, but it lies in a region which was almost unexplored, though one or 